\title{
La superación del nihilismo en la búsqueda del eterno retorno
}

\author{
The overcoming of the nihilism in \\ the search of the eternal return
}

Diego Alfonso Landinez Guio ${ }^{1}$ Universidad Nacional de Colombia, Sede Bogotá Corporación Universitaria Minuto de Dios, CRS

Recepción: 26 de enero del 2018

Evaluación: 12 de febrero del 2018

Aceptación: 29 de mayo del 2018

Filósofo e historiador. Estudiante de Maestría en Filosofía, Universidad Nacional de Colombia. Docente Universidad Nacional y Corporación Universitaria Minuto de Dios, CRS.

Correo electrónico: dalandinezg@unal.edu.co

Landinez, D. (2018). La superación del nihilismo en la búsqueda del eterno retorno.

Cuestiones de Filosofía, 4 (22), 93-115. 


\title{
Resumen
}

El nihilismo y el eterno retorno son conceptos centrales en el intento nietzscheano por comprender el surgimiento y la crisis de los valores, desde el advenimiento de la metafísica y la moral cristiana. Sin embargo, la valoración de estos conceptos dista de ser unívoca en la obra del filósofo alemán, ya que su sola enunciación no es suficiente para alcanzar una de las metas máximas de su pensamiento: la transvaloración. El presente artículo tiene por objetivo examinar los sentidos en los que se habla de nihilismo en algunos pasajes de la obra de Nietzsche y la necesidad conceptual de llegar al pensamiento del eterno retorno como condición necesaria para efectuar la transvaloración; en este sentido, se sustentará la tesis de que el eterno retorno implica tanto la perfección como la superación del nihilismo, en la medida en que logra apartar de sí el resentimiento. Para ello, se mostrará el camino recorrido por el autor para superar la ambivalencia de la debilidad y la fuerza que acompaña el desarrollo de estos conceptos, en parte de la Ciencia Jovial y el tercer libro de Así habló Zaratustra.

Palabras clave: nihilismo, eterno retorno, transvaloración, Nietzsche, resentimiento.

\begin{abstract}
The nihilism and the everlasting return are key concepts in the Nietzschecian attempt to understand the rising and crisis of values, from the coming of the metaphysics and Christian moral. However, the valuation of those concepts is far from being univocal in the work of the German philosopher, since its utterance is not enough to reach one of the greatest goals of his thought: the transvaluation. The current article aims to examine the views in which some readings of the work of Nietzsche speak about nihilism and the conceptual need of reaching the eternal return thought as a necessary condition to perform the transvaluation. In this scenario, the thesis will be based on the eternal return that the everlasting return implies both the perfection and the overcoming of the nihilism, in the manner that it can separate from itself the resentment. For this, it will be shown the traveled path of the author to overcome the ambivalence of the weakness and the strength that come with the development of these concepts, in part from the Gay Science and the third book of Thus Spoke Zarathustra.
\end{abstract}

Keywords: nihilism, eternal return, transvaluation, Nietzsche, resentment. 


\section{Le dépassement du nihilisme dans la recherche de l'éternel retour}

\section{Résumé}

Le nihilisme et l'éternel retour sont des concepts centraux de la tentative nietzschéenne pour comprendre l'émergence et la crise des valeurs, depuis l'avènement de la métaphysique et de la morale chrétienne. Pourtant, l'appréciation de ces concepts est loin d'être univoque dans l'œuvre du philosophe allemand, étant donné que sa seule énonciation ne suffit pas à atteindre un des buts ultimes de sa pensée : la transvaluation. Cet article a pour objectif d'examiner les sens avec lesquels le nihilisme est évoqué dans certains passages de l'œuvre de Nietzsche et la nécessité conceptuelle d'aboutir à l'idée de l'éternel retour comme condition nécessaire à la réalisation de la transvaluation ; en ce sens, nous soutiendrons la thèse que l'éternel retour implique tout autant la perfection que le dépassement du nihilisme, dans la mesure où il parvient à écarter de soi le ressentiment. Pour cela, nous montrerons le chemin parcouru par l'auteur pour surmonter l'ambivalence de la faiblesse et la force qui accompagne le développement de ces concepts, sur une partie du Gai Savoir et du troisième livre d'Ainsi parlait Zarathoustra.

Mots-clés : nihilisme, retour éternel, transvaluation, Nietzsche, ressentiment.

\section{A superação do niilismo na busca do eterno retorno}

\section{Resumo}

O niilismo e o eterno retorno são conceitos centrais na tentativa nietzschiana de compreender o surgimento e a crise dos valores, desde o advento da metafisica e a moral cristã. No entanto, a valoração desses conceitos dista de ser unívoca na obra do filosofo alemão, pois a enunciação não é suficiente para alcançar uma das metas máximas de seu pensamento: a transvaloração. Este artigo tem como objetivo examinar os sentidos nos quais se fala de niilismo em alguns trechos da obra de Nietzsche e a necessidade conceitual de chegar ao pensamento do eterno retorno como condição necessária para efetuar a transvaloração. Nesse sentido, sustentar-se-á a tese de que o eterno retorno implica tanto a perfeição como a superação do niilismo, na medida em que logra pôr de lado o ressentimento. Para isso, mostrar-se-á o caminho percorrido pelo autor para superar a ambivalência da debilidade e da força 
que acompanha o desenvolvimento desses conceitos, em parte da Gaia Ciência e do terceiro livro de Assim falou Zaratustra.

Palavras-chave: niilismo, eterno retorno, transvaloração, Nietzsche, ressentimento. 


\section{Introducción}

El concepto de nihilismo tiene varios sentidos en la obra de Nietzsche: en ocasiones es visto como una manifestación de debilidad, en otras se percibe como un desborde de fuerza; en cualquier caso, aparece como un signo de la vitalidad de quien lo asume y de las metas que traza o de las que se desencadena. Nietzsche advierte la presencia del nihilismo en la cultura europea de su tiempo, pero no como aquel que anuncia la llegada de un completo desconocido, sino como quien pregunta, como lo hace en uno de los fragmentos de 1885-1886, por la procedencia del "más inquietante de todos los huéspedes" $(\mathrm{FP}, 2[127])^{2}$, ya que pronto se revela como un rasgo inherente a la visión moral del mundo: no el efecto de su crisis o de algún tipo de "degeneración" progresiva, sino el desenvolvimiento necesario de aquellos valores que, en su ocaso, dejan ver el "error" que los erigió en fuente suprema de estimación y el tipo de vida "decadente" que los engendró.

Dentro de esta historia de las valoraciones morales, Nietzsche se sitúa a sí mismo en el lugar particular de quien ha experimentado todos los avatares del nihilismo, como el "primer nihilista perfecto de Europa" que deja tras de sí, por la radicalización extrema de sus consecuencias, el desprecio metafísico de la vida. En este sentido, el nihilismo nietzscheano es activo, capaz de minar conscientemente la base de los valores supremos, completo, ya que intenta suprimir lo suprasensible como ámbito de estimación y, por ello, extremo, en tanto interpreta los valores en términos del tipo de vida que los crea. Esta perfección es necesaria en tanto "última consecuencia" de la historia occidental, pues solo esta perspectiva puede determinar "el valor de estos «valores»" 3 en el camino hacia una nueva valoración (FP, 11[411]).

La transvaloración es entonces la apuesta de la filosofía nietzscheana, pero, ¿cómo es posible la superación del nihilismo en su versión más radical y, precisamente, por ella? La clave parece ser el "pensamiento del eterno retorno", que, como afirma Heidegger (2013), es el fundamento del conjunto de la

2 En este artículo se citarán los fragmentos del tomo IV de los Fragmentos Póstumos (FP) de la edición de Tecnos conforme a la numeración allí establecida. Las obras de Nietzsche se referenciarán conforme a las siglas que se indican entre paréntesis al frente de cada una de ellas: Nacimiento de la Tragedia (NT), La Ciencia Jovial (CJ), Así habló Zaratustra (Z), Genealogía de la Moral (GM), Crepúsculo de los ídolos (CI), Anticristo (A).

3 Todas las cursivas y comillas que aparecen en las citas hacen parte de los textos revisados.

Landinez, D. (2018). La superación del nihilismo en la búsqueda del eterno retorno. 
filosofía de Nietzsche (p. 210). Nuestra hipótesis plantea que el eterno retorno implica tanto la perfección como la superación del nihilismo en la medida en que logra apartar de sí el resentimiento, sobre todo a lo largo del tercer libro de Así habló Zaratustra. Para mostrar esta interpretación, el artículo se divide en tres partes: en la primera, se rastrea el origen de la moral como manifestación del resentimiento y la decadencia. En la segunda, se analiza el sentido de la expresión "Dios ha muerto" como forma paradigmática de la desvalorización de los valores y el punto de partida para la perfección del nihilismo. En la tercera, se establece la relación entre nihilismo y eterno retorno a partir de algunos textos de La Ciencia Jovial y la tercera parte del Zaratustra.

\section{La lógica de la venganza}

Una aproximación al nihilismo se encuentra en el fragmento 9[35] de 1887, donde se comprende como la conciencia de que "falta la meta", de que "falta la respuesta al "ipor qué?»", es decir, como una evidencia de que "los valores supremos se desvalorizan", de que ya no es posible saber con certeza qué hay que estimar, pues se ha desdibujado el criterio mismo de lo que es valioso. Pero esta pérdida puede tener dos sentidos: el primero es el de la forma activa, que la asume como una fuerza destructora que busca nuevas metas, dada la insuficiencia de los valores vigentes para el crecimiento de la vida. Su contraparte es el nihilismo pasivo en el que la desvalorización es signo del cansancio: en él la posibilidad de plantear una meta se diluye en la pura desilusión.

Hay también un nihilismo extremo que niega la existencia de la verdad, que elimina de todo valor cualquier correspondencia con lo real y, en cambio, lo concibe como "síntoma de fuerza por parte de quien instituye el valor, una simplificación con el fin de la vida" (FP, 9[39]). Este nihilismo tasa los valores conforme al tipo de vida del que emergen y estima el crecimiento o la debilidad que está a la base de su desvalorización. Desde esta óptica se vislumbra la perspectiva que Nietzsche asume como propia: "El grado de incredulidad, de «libertad de espíritu» admitida, como expresión del crecimiento del poder/«nihilismo» como ideal de potencia suprema del espíritu, de vida exuberante: en parte destructor, en parte irónico (FP, 9[39]).

No el desencantamiento sino la destrucción activa de toda estimación que no contribuya al crecimiento de la vida; el establecimiento crítico del valor 
de los valores como óptica que vislumbra las condiciones que hacen posible toda valoración y, por lo tanto, la transvaloración (Deleuze, 2002; Heidegger, 1995). Sin embargo, la ambivalencia del nihilismo está siempre presente, el peligro que desemboca en su forma incompleta acompaña en todo momento a su contraparte e incluso custodia constantemente al autor del Zaratustra en la formulación del eterno retorno.

La apuesta nietzscheana por el nihilismo perfecto piensa la desvalorización de los valores supremos como el desenlace ineludible de la historia de Occidente; por ello, la reflexión sobre su ocaso está siempre acompañada por la genealogía del origen. En otro fragmento de 1887, Nietzsche concibe la moral como un antídoto que "prevenía que el hombre se despreciara como hombre, que tomara partido contra la vida, que desesperara del conocer: era un medio de conservación" (5[71]). La moral y la metafísica surgen como mecanismos de auto preservación de un tipo de vida particular, como valoraciones de "una vieja voluntad de poder" (Z, II, p. 170), ligadas a condiciones singulares de existencia y sus puntos de vista ${ }^{4}$. ¿Qué tipo de vida es esa? Una cuyo sufrimiento proyecta sus frustraciones en "otro" mundo: "una pobre fatiga ignorante, que ya no quiere ni querer" (Z, I, p. 57). En el origen de la metafísica se halla, por lo tanto, la venganza contra la vida, una voluntad que se niega a sí misma.

La historia de Europa a la que Nietzsche se refiere es, entonces, la historia de los valores que crearon el mundo "verdadero", suprasensible, para contraponerlo al mundo "falso", al devenir. En el Crepúsculo de los ídolos se plantea el problema de este origen: "En todos los tiempos los sapientísimos han juzgado igual sobre la vida: no vale nada... Siempre y en todas partes se ha oído de su boca el mismo tono, - un tono lleno de duda, lleno de melancolía, lleno de cansancio de la vida, lleno de oposición a la vida" (CI, p. 37).

\footnotetext{
4 Toda valoración es expresión de una relación de mando y obediencia, cuyo principio de diferenciación es una voluntad de poder, ya sea afirmativa o negativa (Deleuze, 2002, pp. 72-73); ello implica que la distancia entre un tipo de valoración y otra se cualifica por el carácter afirmativo o negativo de la voluntad y por el equilibrio entre lo activo y lo reactivo de las fuerzas que entran en relación. En este sentido, la indagación genealógica de Nietzsche rastrea la naturaleza de la voluntad de poder que edifica un determinado conjunto de valores. Así, la apuesta por la transvaloración significa para Nietzsche "un cambio en el elemento del que deriva el valor de los valores" (Deleuze, 2002, p. 221), es decir, un paso decisivo de lo negativo hacia lo afirmativo.
}

Landinez, D. (2018). La superación del nihilismo en la búsqueda del eterno retorno. 
Y líneas más adelante se pregunta: “¿Acaso es que la sabiduría aparece en la tierra como un cuervo, al que un tenue olor a carroña lo entusiasma?" (CI, p. 38). Quienes entran en escena son Sócrates y Platón como "tipos" de la decadencia de los instintos de la antigua Grecia. La figura de Sócrates es vista allí como signo del resentimiento plebeyo que utilizaba sus mejores armas, la ironía y la dialéctica, como instrumentos de venganza frente a lo aristocrático que existía en la cultura helénica.

Ya en el Nacimiento de la tragedia, Sócrates es caracterizado como la fuerza disolvente de lo trágico, como el tipo de una nueva forma de vida: el "ser humano teórico", que se edifica en la "creencia inquebrantable" según la cual, "siguiendo el hilo de la causalidad, el pensar alcanza los abismos más hondos del ser, y que el pensar está en condiciones no sólo de conocer, sino incluso de corregir el ser" (NT, p. 396). Esta perspectiva se muestra, a la mirada nietzscheana, como signo del agotamiento frente a la fortaleza que reflejaba el mito trágico y su sabiduría silénica: “¿Es quizá el cientificismo solamente un miedo y una evasiva frente al pesimismo? ¿Una refinada y legítima defensa -contra la verdad?" (NT, p. 330).

El socratismo llega en una época de cansancio, una en la que se pierde el rumbo de aquella vida trazada por el hombre trágico que afirmaba heroicamente "el remolino devorador del devenir" (Cruz Vélez, 1985, p. 108). Como respuesta a este agotamiento vital, Sócrates inventó un sentido más allá del mundo para orientar a las naturalezas débiles y desesperadas, pues "comprendió que todo el mundo tenía necesidad de él, - de su remedio, de su cura, de su ardid personal para autoconservarse" (CI, p. 41). Al desgaste de los instintos del hombre trágico, y contra ellos, la racionalidad socrática respondió con la desvalorización de la vida como mecanismo para no perecer: su respuesta fue el falseamiento metafísico-moral de la realidad.

Este primer brote de nihilismo, donde el devenir queda despojado de sentido y de cualquier meta inherente, se erige esencialmente como "la empresa de negar la vida, de despreciar la existencia" (Deleuze, 2002, p. 48), cuyas formas fundamentales son el resentimiento, la mala conciencia y el ideal ascético, objeto de los tres tratados que componen la Genealogía de la moral. Desde esta óptica, Nietzsche rastrea el origen de la antítesis bueno-malo y muestra que los estamentos de rango superior acuñaron la palabra "bueno" para distinguirse a sí mismos, partiendo de un "pathos de la distancia", de lo bajo y vulgar, que concibieron como "lo malo" (GM, I, pp. 31-32). 
El concepto de lo bueno no se relaciona en su origen con ninguna connotación altruista, sino que florece en campos aristocráticos, en aquellas fuerzas activas que se imponen, por acción de su propia positividad, sobre las débiles, cuyo rasgo esencial es la reactividad y la negación. Es el instinto sacerdotal lo que identifica la bondad con la miseria, por lo que, desde su perspectiva, "los que sufren, los indigentes, los enfermos, los deformes son también los únicos piadosos, los únicos benditos de Dios", mientras que los nobles serían "para toda la eternidad, los malvados [...] eternamente los desventurados, los malditos y condenados" (GM, I, pp. 39-40). Es el resentimiento y el odio que destilan las naturalezas más bajas y maltrechas lo que permite la inversión valorativa que eleva a mérito la debilidad para sembrar la culpa entre los fuertes: del odio judío y la venganza de su dios, brutalmente asesinado en la cruz, nace el amor cristiano para recoger sus frutos, pues los guía idéntica finalidad.

La mala conciencia es una objeción a la vida ascendente esgrimida con odio por la decadencia en la búsqueda del poder, es el instrumento que los sacerdotes han utilizado para postrar a los fuertes a su designio, pero es una objeción que tiene como finalidad conservar la vida de la que nace. Para mandar, los hombres del ideal ascético tienen que debilitar a los fuertes, dada su incapacidad para la fortaleza: dentro de sí el resentimiento explota como una venganza que triunfa una vez que logra "introducir en la conciencia de los afortunados su propia miseria, toda miseria en general: de tal manera que éstos empezasen un día a avergonzarse de su felicidad" (GM, III, p. 144). Pero este ideal, presente en todas las épocas y estamentos, se yergue como una necesidad de sentido: es la fórmula que el hombre ha encontrado para no desesperar de su sufrimiento, pues en ella "aparecía interpretado; el inmenso vacío parecía colmado; la puerta se cerraba ante todo nihilismo suicida" (GM, III, p. 185).

El ideal ascético fue el antídoto contra el nihilismo primero, la respuesta ante su falta de sentido, pero una respuesta en sí misma nihilista, un contrasentido que difamaba la vida para mantener lo más débil en ella, pues la negación de la vida brota de la vida misma. El ascetismo no es, pues, una falta de voluntad, sino una "voluntad de nada" (GM, III, p. 186), una vida que se interpreta a sí misma como nada para perpetuar su decadencia y enseñorearse sobre lo fuerte. Este instinto de conservación se manifiesta de manera práctica en la compasión, valor típicamente cristiano que le sirve de bastión a la conservación de lo degradado. La compasión es "la praxis del nihilismo", es el 
"instrumento capital para la intensificación de la décadence [...] No se dice «nada»: se dice, en su lugar, «más allá»; o «Dios»; o «la vida verdadera»" (A, pp. 31-32): quien fracasa en la realidad huye como santo hacia la nada.

El sacerdote judío falsea la idea de Dios, impone con ella su voluntad y los valores que permiten perpetuar su propia vida; con ellos se enfrenta a Roma y se apodera de ella. Jesús y Pablo son los nombres que permiten al cristianismo llevar a cabo su cometido. Para Nietzsche, Jesús de Nazaret no era más que la expresión de la decadencia; su evangelio era el de los cansados que han aprendido a morir sin oponer resistencia. Su muerte no fue otra cosa que la prueba de su práctica vital: "No defenderse, no encolerizarse, no hacer-responsable a nadie... Por el contrario, no oponer resistencia ni siquiera al malvado, - amarlo" (A, p. 65). Fueron sus seguidores quienes concibieron la muerte del Cristo como una refutación de la doctrina, quienes introdujeron la venganza como rasgo fundamental de un credo e inventaron la resurrección y la promesa de la inmortalidad personal. Una vez más el sacerdote judío se impuso. En la figura de Pablo, el cristianismo se hizo fe para tiranizar la realidad: "Vivir de tal modo que ya no tenga sentido vivir, eso es lo que ahora se convierte en el «sentido» de la vida..." (A, p. 74).

\section{La muerte de Dios: entre el nihilismo incompleto y el nihilismo perfecto}

Para Nietzsche, el dominio de la metafísica y la moral perfecciona una voluntad de verdad que se manifiesta en la identificación del "más allá" como "mundo verdadero". Esto pone en entredicho la diferencia de naturaleza entre la ciencia y la religión, dado que, según él: "nosotros los que conocemos, hoy en día, nosotros ateos y antimetafísicos, aún tomamos nuestro fuego también de aquel incendio encendido por una creencia de milenios $[\ldots]$ de que Dios es la verdad" (CJ, V, p. 344). La ciencia, el conocimiento y el ateísmo no son polos opuestos de la metafísica, sino los frutos finales del ideal ascético que terminan volviéndose en su contra: "es la catástrofe, que impone respeto, de una bimilinaria educación para la verdad, educación que, al final, se prohíbe a sí misma la mentira que hay en el creer en Dios" (GM, III, p. 183). Los valores nihilistas decaen por el desarrollo de su propia naturaleza: es la voluntad negadora que se niega a sí misma.

Llega entonces una época en la que son propicias las condiciones para una nueva inversión valorativa, una época en la que es posible llevar a cabo una transvaloración, dado que la fuerza que ya se ha acumulado hace "indecente" 
la creencia en el cristianismo (A, p. 67). Dios es aquí, en la modernidad, la víctima en sacrificio para la redención del hombre: "En realidad no tenemos ya necesidad de un antídoto contra el primer nihilismo: la vida ya no es hasta tal grado incierta, azarosa, absurda en nuestra Europa [...] el poder alcanzado por el hombre permite ahora una disminución de los métodos de disciplina $[\ldots]$ «Dios» es una hipótesis demasiado extrema" (FP, 5[71]).

El anuncio de la muerte de Dios se halla en el aforismo 125 de la Ciencia Jovial. La crudeza de lo que allí se revela tiene un propósito que Heidegger (2013) pone de manifiesto en su explicación sobre la "jovialidad", concepto que hace referencia "a la alegre serenidad de una superioridad que no se desploma ante lo más duro y terrible [...] sino que, antes bien, se fortalece con ello, afirmándolo en su necesidad" (p. 222). En efecto, la noticia de este deicidio tasa la fortaleza de una época amenazada en todo momento por la debilidad; por tal motivo, es un "hombre frenético", en la búsqueda de Dios, quien tiene que recordar el crimen cometido.

El aforismo en cuestión inicia con una crítica a aquellos "maleantes públicos «que no creen en Dios»", que niegan su existencia porque ya no pueden buscarla, porque tienen miedo a pensar y, con ello, a encontrar la fuente de lo divino (Heidegger, 1995, p. 198). El texto nietzscheano sugiere que aquellos "ateos" no dimensionan la importancia del acontecimiento que se revela ante ellos, precisamente porque no tienen claro aquello en lo que dicen no creer. Así pues, ¿quién es Dios? Para Heidegger (1995) es el mundo suprasensible en su totalidad y la frase "Dios ha muerto" implica la crisis de la capacidad vinculante de dicho mundo.

El problema de la relación de Dios y la totalidad de lo suprasensible se desarrolla en el Crepúsculo de los ídolos a propósito de su crítica a G. Eliot. De acuerdo con Nietzsche, los ingleses creen posible superar a Dios manteniendo intacta la moral, lo que a su parecer es una inferencia errada si se piensa que el cristianismo "es un sistema, una visión de las cosas coherente y total. Si se arranca de él un concepto capital, la fe en Dios, se despedaza con ello también el todo", pues no es un concepto entre otros, sino su principio de legitimidad. Si los ingleses consideran que pueden saber por algún tipo de intuición qué es lo bueno y lo malo "en sí", si piensan "que ya no tienen necesidad del cristianismo como garantía de la moral, eso mismo es consecuencia del dominio del juicio cristiano de valor y expresión de la fortaleza $y$ profundidad de ese juicio" (CI, p. 88). De nuevo, es la vieja voluntad de 
poder negadora lo que habla por la boca del moralismo inglés que solo en apariencia ha podido superar al cristianismo.

Por lo tanto, la muerte de Dios expone el carácter ilusorio de toda metafísica, pues ya no procura explicación ni imperativo moral alguno que sea honestamente creíble: es un acto de fuerza en el que se asesta un golpe mortal a los valores que sirvieron de soporte existencial a Occidente desde hace más de dos milenios; pero esta misma razón hace que tal acto revista un aspecto terrible que el hombre frenético no duda en hacer manifiesto: "¿Quién nos dio la esponja para borrar todo el horizonte? ¿Qué hicimos cuando desencadenamos esta tierra de su sol? ¿Hacia dónde se mueve ahora? ¿Hacia dónde nos movemos nosotros? ¿Lejos de todos los soles? [...] ¿No erramos como a través de una nada infinita? ¿No nos sofoca el espacio vacío?” (CJ, III, p. 212).

Las preguntas tienen una connotación pesimista de quien ha perdido su horizonte y ya no sabe qué hacer, pues: "Lo más sagrado y lo más poderoso que hasta ahora poseía el mundo sangra bajo nuestros cuchillos". Tales preocupaciones traslucen la falta de sentido que la muerte de Dios ha legado, la impotencia inmediata para mostrar la dirección de uno nuevo y, por lo tanto, la incertidumbre del devenir sin un ámbito suprasensible que lo guíe. Por supuesto, hay una valoración del crimen: "¡Nunca hubo un hecho más grande; y quienquiera nazca después de nosotros pertenece por la voluntad de este hecho a una historia más alta que todas las historias habidas hasta ahora!" (CJ, III, p. 212), pero también una constatación de la dificultad que encuentran los hombres modernos para trazar una nueva meta: "Este hecho les es todavía más lejano que la más lejana estrella, ¡y sin embargo, ellos mismos lo han hecho!" (CJ, III, p. 213).

La muerte de Dios es una condición necesaria pero no suficiente para la instauración de nuevas metas, ya que para ello se requiere de la capacidad para asumir la grandeza del hecho y poder abolir toda referencia a lo suprasensible; es, por lo tanto, la destrucción que se debate en una disyuntiva: o bien se interpreta como una desilusión producto de la debilidad o se entiende como un acto de fuerza que reconoce en el devenir la única realidad. En todo caso, es una doble valoración que acompaña simultáneamente a la conciencia del acontecimiento y que requiere de otro elemento (el eterno retorno) para poder efectuar la transvaloración.

Como expresión del nihilismo pasivo el deicidio moderno redunda en la búsqueda de "OTRA autoridad que sepa hablar incondicionadamente, que 
pueda ordenar metas y tareas" (FP, 9[43]), es decir, en la instauración de otro más allá: la moral, la razón, el progreso, el socialismo, etc., que elude la responsabilidad de trazar una meta propia: es el nihilismo incompleto que reemplaza el viejo Dios con la condición de mantener intactas las promesas transmundanas de los nuevos ideales. Por consiguiente, el instinto que guía esta destrucción de los valores es el mismo que los fundó (el resentimiento) y reniega de ellos sumido en la frustración melancólica que despoja de todo sentido al devenir porque no vale por sí mismo. Cuando el mundo "verdadero" se revela como falso, el mundo "aparente" pierde todo valor, pues la ruina del mundo suprasensible es insoportable para el tipo decadente, para el débil y cansado, que fundaba en él su propia supervivencia. El resultado de esta crisis: la catástrofe (Ávila Vásquez, 2015).

Pero del mismo hecho, la valoración nietzscheana parece afirmar todo lo contrario del nihilismo incompleto: la muerte de Dios se muestra como un acontecimiento de importancia capital para la humanidad (el más grande de su historia), como el signo de una existencia más alta en la que puede encontrar su camino y afirmar su propia virtud. Nietzsche anuncia una época con una voluntad de poder capaz de trazar metas desde sí misma, que no necesita de un horizonte suprasensible para superarse, pero también advierte el gran peligro de la debilidad, del nihilismo que nace del cansancio: "Dios ha muerto, ésta es la causa del mayor peligro: ¿qué? ¡también podría ser causa del mayor ánimo!" (FP, 2[129]). Para sortear esta ambivalencia, su pensamiento se encamina hacia otra perspectiva capaz de desencadenar la potencia necesaria para instaurar los valores que afirmen el devenir.

El nihilismo de la fuerza es aquel que, a diferencia del anterior, se enfrenta a lo terrible sin rencor ni mala conciencia. En el fragmento 10[3] de 1887, Nietzsche explica su "nueva versión del pesimismo" como "una búsqueda voluntaria de los aspectos terribles y cuestionables de la existencia" que sirve de medida de la fortaleza de quien los contempla. Según él, este pesimismo "podría desembocar en esa forma de decir sí dionisiaco al mundo tal como es: hasta el deseo de su absoluto retorno y eternidad". Lo más siniestro de la existencia se muestra, desde esta perspectiva, no como un motivo para su negación, sino como la razón máxima para su afirmación: la muerte de Dios se convierte, así, en la justificación de la vida a partir de sí misma.

El nihilismo perfecto de Nietzsche señala el último estertor de la metafísica: con él la negación cristiana de la vida devela su propia nada, el instinto de 
verdad desarrollado a lo largo de su historia termina por mostrar que tras las grandes palabras, metas e ideales se hallaba el no $\operatorname{ser}^{5}$, que sus promesas y esperanzas eran irrealizables. La moral sucumbe, al final, a su propia debilidad y arrastra consigo toda otra posibilidad de sentido: "la inviabilidad de una interpretación del mundo a la que se ha dedicado una enorme fuerza - despierta la sospecha de que sean falsas todas las interpretaciones del mundo" (FP, 2[127]). Nietzsche interpreta la voluntad de nada como síntoma de un tipo de decadencia que valora la vida a partir de sus propias condiciones. Ello es posible a partir de dos premisas, a saber: primero, que es imposible tasar el valor de la vida para cualquier naturaleza y, segundo, que el esfuerzo por emprender dicha valoración expresa la fuerza o la debilidad del punto de vista que la realiza (CI, p. 57).

La destrucción absoluta de los antiguos valores y su ámbito suprasensible es un paso necesario hacia la transvaloración si procede, por lo tanto, de la fortaleza de quien la asume: "«Nihilismo», pensado de modo clásico, significa ahora [...] la liberación de los valores anteriores como liberación hacia una transvaloración de todos (esos) valores" (Heidegger, 2013, p. 552). En este sentido, la idea del eterno retorno como elemento faltante para la transvaloración se muestra a la vez como radicalización y como superación del nihilismo (Pérez Mantilla, 2000).

\section{El eterno retorno y la superación del resentimiento}

Si la muerte de Dios hace patente el derrumbe del mundo suprasensible, el descrédito de todo valor, de toda interpretación de lo ente, ¿qué queda? La pérdida de sentido del mundo que conlleva a una verdad insoportable que en un primer momento se muestra solo como posibilidad: el eterno retorno. Si no hay un Dios, si su creencia ha perecido por la acción misma de los hombres, por su fortaleza parcialmente reconocida, el mundo debe ser explicado por sí mismo, es decir, a partir de sus singularidades inmanentes, de sus fuerzas, movimientos y tiempos, sin recurrir a una instancia suprema que le imprima un orden.

\footnotetext{
5 En la parte final de "la «razón» en filosofía", en el Crepúsculo, Nietzsche asegura: "Los signos distintivos que han sido asignados al «ser verdadero» de las cosas son los signos distintivos del no-ser, de la nada, - a base de ponerlo en contradicción con el mundo real es como se ha construido el «mundo verdadero»: un mundo aparente de hecho, en cuanto es meramente una ilusión ópticomoral" (CI, p. 50).
} 
El argumento de Nietzsche parte, en este sentido, del carácter limitado de los elementos que componen el mundo: "Si es lícito pensar que el mundo sea pensado como una determinada cantidad de fuerza y como un determinado número de centros de fuerza [...] de ello se deriva que ha de recorrer un número calculable de combinaciones, en el gran juego de dados de la existencia" (FP, 14[188]).

La limitación de lo ente y sus relaciones en un tiempo infinito lleva a la afirmación del eterno retorno, dado que el conjunto de combinaciones que puedan darse es igualmente limitada, aunque el número de las mismas pueda ser inmensamente grande; sin embargo, a partir de la premisa de un tiempo infinito, se concluye que "toda posible combinación se habría alcanzado una vez, en algún momento; más aún, se habrían alcanzado infinitas veces" (FP, 14[188]). Sin la guía de lo trascendente, el orden del mundo se explica por la inercia de su movimiento intrínseco, ciego, repetitivo y eterno.

De acuerdo con el análisis de Pérez Mantilla (2000), esta es la aproximación "cosmológica" del eterno retorno, aquella que intenta explicar el funcionamiento del universo a partir de una "base científica" (p. 5); pero también es una explicación que evidencia su connotación extrema y pesimista, ya que concluye en el absoluto vacío de sentido: aquel que retorna infinitas veces: “¡la nada [...] eternamente!” (FP, 5[71]).

La muerte de Dios conduce a la verdad del eterno retorno y este, como aque1la, también es presa de la ambivalencia del nihilismo de la fuerza y de la debilidad. Desde su primera comunicación en la Ciencia Jovial, Nietzsche vislumbra la doble lectura de dicho concepto y su papel en la superación del pesimismo. Quizá pueda establecerse una relación entre los tres últimos parágrafos del libro cuarto de dicha obra para notar la centralidad del eterno retorno en la historia de Occidente, sus posibles interpretaciones y el camino que, a partir de tal revelación, debe seguir Zaratustra en la configuración del más grave de sus pensamientos.

En el aforismo 340, titulado "Sócrates moribundo", Nietzsche señala el desprecio de la vida que nace en la filosofía griega, es decir, el inicio de la historia de la decadencia. Su sospecha parte de las últimas palabras pronunciadas por Sócrates antes de su muerte: "Oh, Critón, debo un gallo a Asclepio". La interrogación nietzscheana desea desenmascarar su contenido y sus implicaciones para establecer de qué tipo de vida provienen. Su diagnóstico es que Sócrates era pesimista: “iy a lo largo de su vida había escondido su último 
juicio, su más íntimo sentimiento! Sócrates, ¡Sócrates padeció la vida! Pero se vengó de eso, ¡con aquellas palabras veladas, espantosas, piadosas y blasfemas!" (CJ, IV, p. 333). La metafísica nace de esa venganza contra la vida; por ello la reflexión termina con la consigna: “¡También tenemos que superar a los griegos!” (CJ, IV, p. 334), pero, ¿cómo terminar con la historia inaugurada por Sócrates y eternizada por Platón?

"La mayor gravedad", el parágrafo 341, señala la respuesta. Por la boca de un demonio se insinúa el eterno retorno, la posibilidad de que la vida tal como se ha vivido, con sus placeres y dolores, regrese "innumerables veces más". De inmediato, Nietzsche dimensiona las consecuencias de este pensamiento: “¿No te arrojarías al suelo y rechinarías los dientes y maldecirías al demonio que así te habla? ¿O has tenido la vivencia alguna vez de un instante terrible en que le responderías: « ¡Eres un Dios y nunca escuché nada más divino!»?” (CJ, IV, p. 334).

Cada respuesta depende del grado de fortaleza que tenga quien lo asume. Así como la muerte de Dios hace parte de una historia más alta, aunque insoportable para los transmundanos, el eterno retorno constituye un pensamiento que no deja indemne a quien lo piensa: "Si aquel pensamiento llegara a tener poder sobre ti, así como eres, te transformaría y tal vez te trituraría”. Quizá el mayor de los males, quizá la mayor de las esperanzas, en todo caso, la pregunta por el deseo de la eterna repetición de lo vivido "¡recaería sobre tu acción como la mayor gravedad!" (CJ, IV, p. 335). Es un peso que puede paralizar la acción en una especie de "fatalismo" (Heidegger, 2013, p. 316) o puede, para quien asuma el "quieres" de este cuestionamiento, ser la suprema posibilidad de que cada instante decida lo que retorna en la eternidad.

La lucha de estas dos valoraciones es el inicio del camino de Zaratustra, la "Incipit Tragoedia", que constituye el final del libro cuarto de la Ciencia Jovial (\$342) y el prólogo, con algunas modificaciones, de Así habló Zaratustra. Allí, Nietzsche se embarca en la búsqueda del eterno retorno recorriendo el camino que va desde la consciencia de la muerte de Dios y el advenimiento del superhombre, con toda la exposición crítica de la moral vigente y la metafísica, hasta la afirmación de la voluntad de poder como "carácter fundamental del ente" (Heidegger, 2013, p. 29). Pero en esta búsqueda, Zaratustra se encuentra con el espíritu de la pesadez, con el pesimismo y la debilidad, siempre presente en la interpretación de su doctrina. A lo largo del Zaratustra, Nietzsche intenta apartar de su pensamiento el nihilismo pasivo y 
los elementos que le son inherentes: la venganza y el resentimiento, instintos presentes en los valores modernos del nihilismo incompleto que amenazan su propia doctrina ${ }^{6}$.

La voluntad de poder propone una interpretación del mundo que lo libera de las cadenas de lo suprasensible e imprime un rasgo fundamental a la vida: "Crear - esa es la gran redención del sufrimiento" (Z, II, p. 133); toda metafísica se asume como un conjunto de valores que sirven de condición de conservación a un determinado punto de vista, pero nada más allá del crear mismo. Con la afirmación de la voluntad de poder como fundamento de lo que existe, la muerte de Dios adquiere un nuevo sentido, puesto que se lee como la posibilidad máxima de redención del devenir, dado que de ella emerge la afirmación de la vida: "quien tiene que ser un creador en el bien y en el mal: en verdad, ése tiene que ser antes un aniquilador y quebrantador de valores" (Z, II, p. 172). Es un paso necesario hacia el nihilismo activo.

Pero el pesimismo es un peligro constante, sobre todo cuando el cansancio y la debilidad se ciernen entre los hombres. La figura del "adivino" es el signo de una nueva decadencia, de una "gran tristeza" que se posa sobre la humanidad y que se presenta ante Zaratustra: "Una doctrina se difundió, y junto a ella corría una fe: 'todo está vacío, todo es idéntico, todo fue"” (Z, II, p. 197). La aniquilación pesimista de valores se asoma como un motivo para reforzar el resentimiento.

La voluntad es un liberador que demanda la redención del pasado: frente a él es seducida por la venganza contra aquello que no puede cambiar ni dominar; este es el resentimiento de "los lisiados y los mendigos" que piden a Zaratustra descargar sus pesos. Pero el horizonte de la nueva valoración del pasado no enseña a liberarse de los fardos sino a aprender a quererlos tal como han sido: "Todo 'fue' es un fragmento, un enigma, un espantoso azar - hasta que la voluntad creadora añada: 'ipero yo lo quise así!’” (Z, II, p. 206). La voluntad trae consigo una mala conciencia que el eterno retorno agudiza: la omnipresencia del pasado y su repetición eterna sin sentido. La búsqueda de Zaratustra se enfoca, entonces, en la descarga de la pesadez que

\footnotetext{
6 Esta amenaza se hace patente en el inicio de la segunda parte del Zaratustra. En el niño del espejo Zaratustra advierte que su pensamiento es presa de la desfiguración y que debe buscar nuevos caminos. Ante el espejo que el niño le acerca en sueños, Zaratustra ve una imagen aterradora: "pues no era a mí a quien veía en él, sino la mueca y la risa burlona de un demonio" (Z, II, p. 128). Es la prefiguración del "mono" que enfrentará en la tercera parte.
}

Landinez, D. (2018). La superación del nihilismo en la búsqueda del eterno retorno. 
en cada momento trae su propio pensamiento, la búsqueda del sagrado "sí" solo desde el cual el desprecio que implica el "no" del nihilismo se convierte en signo de una fuerza activa.

Abrazar el eterno retorno, aceptar su ominosa necesidad, es propio de una voluntad de poder afirmativa, ya que cataliza sus fuerzas creativas: es el pensamiento que mide su potencia o revela su negatividad; por consiguiente, es también la condición de posibilidad para la transvaloración, pues aún necesita redimirse de la mala conciencia del pasado y de todo concepto de culpa: es la prueba de fuego de la voluntad que sale al encuentro de Zaratustra cuando ha logrado madurar para ello, es decir, en la más silenciosa de las horas.

Desde el comienzo de la tercera parte del Zaratustra, Nietzsche asume la tarea de enfrentar lo siniestro como un paso necesario para llegar a su madurez. El enigma que comunica por segunda vez al eterno retorno se sitúa en el "crepúsculo de color de cadáver", allí donde "más de un sol se había hundido en su ocaso para mí" (Z, III, p. 224). El punto de partida es, pues, la suerte de Dios en las manos deicidas del hombre moderno. Ahora, en la superación del aire sepulcral que rodea tal crimen, Zaratustra asciende por un sendero "maligno y solitario" donde el peligro de resbalar está siempre presente. Las palabras no son casuales. Denotan la magnitud de la empresa que se lleva a cabo, pues la cima está siempre amenazada por el abismo sobre el que se alza.

La dirección es ascendente, pero de las profundidades Zaratustra lleva algo consigo: "ese espíritu, mitad enano, mitad topo; paralítico; paralizante" (Z, III, p. 224), que le sentencia burlonamente la caída de todo lo que se dirige a lo alto. La superación del nihilismo no es fácil, el peligro de ser atraído por el pesimismo del adivino es inminente y se lleva consigo una vez se baja a los abismos. Zaratustra desenfunda su valor y plantea la disyuntiva: “¡Enano! ¡Tú! ¡O yo!”. En efecto, el mayor peligro es la compasión, ya que "cuanto el hombre hunde su mirada en la vida, otro tanto la hunde en el sufrimiento". Ese valor que "ataca" enfrenta lo terrible con una clara determinación: "¿Era esto la vida? ¡Bien! ¡Otra vez!” (Z, III, p. 225). Una vez más, Nietzsche asume el nihilismo activo como condición necesaria para llegar a la plenitud de su pensamiento, como la actitud que afirma la vida con el sufrimiento que le es sustancial y que, en su demasía de fuerza, es capaz de superar los obstáculos impuestos por la dureza del camino recorrido. Es la redefinición del pesimismo llevado a la práctica. 
Zaratustra señala aquel punto llamado Instante, en el que confluyen dos eternidades: el pasado y el futuro. El enano interpreta erróneamente este pensamiento como un círculo, es decir, desde la pesadez que lo conduce a la fatalidad y a la inacción: es un pesimismo que sube a la par que la fortaleza. Pero la voluntad quiere redimirse del pasado y es esa la dirección que toma el pensamiento del retorno: "Desde este portón llamado Instante corre hacia atrás una calle larga, eterna: a nuestras espaldas yace una eternidad" (Z, III, p. 226). De la conciencia del pasado y del quererlo innumerables veces debe nacer la fortaleza, no de su negación.

El episodio de la superación de la pesadez se consigna en la parte final de "De la visión y del enigma", con la escena del pastor a quien ha mordido una serpiente en la garganta. El cuadro no puede ser más siniestro y tiene lugar en la media noche, aquel momento de mayor peligro que enfrenta la debilidad y la fortaleza, "cuando incluso los perros creen en fantasmas" (Z, III, p. 227), el fantasma de nuevos ideales ${ }^{7}$. La revelación decisiva del eterno retorno hace pensar en el pesimismo amenazante, pues es la serpiente que muerde al pastor, el nihilismo que se aferra con fuerza, absorbe la vitalidad de su víctima y termina en la apología de la muerte, incluso en el arte (Ávila Vázquez, 2015).

El hombre de cuya garganta pende la pesadez es el mismo Zaratustra que busca superar la fatalidad que aún lo acompaña. Por esto, el eterno retorno toma la forma del mordisco que le quita la cabeza a la serpiente. El mordisco es el instante en el que se decide en cada caso el pasado y el futuro que confluyen en él, se genera gracias al nihilismo que destruye los valores y es al mismo tiempo la superación de su dimensión puramente destructora (Heidegger, 2013, p. 357), es el supremo acto de fortaleza que transfigura a quien lo realiza: el terror ha devenido en risa.

Lo que se plantea en forma de enigma va tomando una forma más definida en las siguientes secciones de la tercera parte del Zaratustra. En "De la bienaventuranza no querida" se plantea explícitamente que su pensamiento fundamental es aquello que muerde y estrangula, "imas alguna vez -dice el autor- debo encontrar la fuerza y la voz del león, que te llame arriba!” (Z, III, p. 231). La fuerza está acumulada, falta aún el valor que se atreva a vencer la

7 El terrorífico aullar de los perros es, para Heidegger (2013), una referencia a la influencia de Schopenhauer y Wagner en el joven Nietzsche (p. 353).

Landinez, D. (2018). La superación del nihilismo en la búsqueda del eterno retorno. 
pesadez. Más adelante, se indica el horizonte de la nueva valoración: fuera de toda estructura suprasensible que pretenda imponer un orden arbitrario como esencia del mundo, es decir, más allá del bien y del mal: "Una bendición es y no una blasfemia el que yo enseñe: «Sobre todas las cosas está el cielo Azar, el cielo Inocencia, el cielo Acaso y el cielo Arrogancia». «Por acaso»-esta es la más vieja aristocracia del mundo, y yo se la he restituido a todas las cosas, yo la he redimido de la servidumbre a toda la finalidad" (Z, III, p. 235).

Es el nihilismo perfecto que a la par que el eterno retorno va emergiendo de su abismo, la negación completa de todo ideal transmundano que se superpone como tela de araña a la inocencia del puro devenir.

Dos aspectos realzan la dirección hacia la cual apuntan la voluntad de poder y el eterno retorno: la superación de la resignación y el resentimiento. Frente a las virtudes modernas que buscan la felicidad como tibio bienestar, Nietzsche opone aquellos que aprenden a obedecerse a sí mismos contra toda forma de cobardía e hipocresía que hace al hombre el animal doméstico por excelencia. La redención del pasado no implica resignarse a él, sino quererlo en la máxima decisión del instante. Este camino lleva a Zaratustra al mayor peligro del resentimiento: su propia doctrina en manos de la quien llaman su "mono". En "Del pasar de largo", se advierte claramente la especificidad del "desprecio" nietzscheano.

En efecto, las palabras de Zaratustra en boca del mono esputan venganza, no un despreciar genuino: en él la crítica adquiere la forma del resentimiento de quien no ha sido adulado lo suficiente por aquellos que dice despreciar y que se sitúa a su vera con el propósito exclusivo de destilar su odio. Son las palabras de Zaratustra usadas por el rencor para ultrajar. Por esta razón, vuelve a apuntar la dirección correcta de su crítica: "Sólo del amor deben salir volando mi despreciar y mi pájaro amonestador: ¡pero no de la ciénaga!” (Z, III, p. 250). Si de sus palabras se apropia una voluntad negativa y sus fuerzas reactivas, Nietzsche sugiere mejor pasar de largo.

En "El convaleciente", Zaratustra recibe el título de "maestro del eterno retorno" (Z, III, p. 303), allí su pensamiento muestra el aspecto más inquietante y la fortaleza del león se enfrenta a su mayor abismo, la transfiguración del pastor del enigma muestra su última pesadez, el hastío del hombre: “«Eternamente retorna él, el hombre del que estás cansado, el hombre pequeño» - así bostezaba mi tristeza y arrastraba el pie y no podía adormecerse" (Z, III, p. 301). 
El eterno retorno trae consigo la afirmación de un volver incluso de lo más bajo, de aquello que es despreciado por la voluntad afirmativa. Por ello, el querer tiene que redimir también a quien lo enseña de una última mala consciencia. En este sentido, tanto la sabiduría como el orgullo, es decir, los animales de Zaratustra, pueden mostrar la afirmación del terrible pensamiento: "vendré eternamente de nuevo a esta misma e idéntica vida, en lo más grande y también en lo más pequeño, para enseñar de nuevo el eterno retorno de todas las cosas" (Z, III, p. 303). Mas en la inocencia del devenir, el retorno cambia de signo y la pesadez se vuelve ligereza, es un retorno "selectivo" (Deleuze, 2002).

Solo con la superación de la debilidad, el resentimiento y la venganza, puede el eterno retorno asumir una posición activa tanto en la destrucción como en la transvaloración. El camino de Zaratustra, en la búsqueda de su pensamiento más terrible, consistió en dicha transfiguración, en asumir la afirmación del devenir desde sí mismo, reinterpretando tanto la muerte de Dios como el eterno retorno, para la redención completa de la voluntad de poder y la instauración de nuevas condiciones de conservación y crecimiento. Por ello, se dice al final de la tercera parte en "Los siete sellos (O: la canción del «Sí y Amén»)", ya sin pesadez, sin resentimiento ni melancolía, palabras similares a las del hombre frenético, pero cuyo sentido ha cambiado por completo, a la luz de su arraigo en una voluntad de poder afirmativa:

Si alguna vez extendí silenciosos cielos encima de mi, y con alas propias volé hacia cielos propios:

Si yo nadé jugando en profundas lejanías de luz, y mi libertad alcanzó una sabiduría de pájaro: -

- y así es como habla la sabiduría de pájaro: «iMira, no hay ni arriba ni abajo! ¡Lánzate de acá para allá, hacia adelante, hacia atrás, tú ligero! ¡Canta! [...]»

Oh, ¿cómo no iba yo a anhelar la eternidad y el nupcial anillo de los anillos, - el anillo del retorno? (Z, III, p. 318).

Con la elaboración hecha en el tercer libro del Zaratustra se llega al eterno retorno como el pensamiento más terrible, como el más completo de los nihilismos y al mismo tiempo como la suma afirmación del devenir, pues se debatía entre el absoluto sinsentido y la afirmación de la vida en el sinsentido mismo: "Con la absoluta afirmación del devenir, logra Nietzsche golpear al nihilismo en su centro [...], estableciendo paradójicamente una eternidad 
temporal, opuesta a la eternidad intemporal de la metafísica, que le permite afirmar de manera total el mundo" (Pérez Mantilla, 2000, p. 18).

Únicamente como proceso de superación continua de las fuerzas reactivas de la vida se puede comprender el nihilismo y su conexión con el eterno retorno como fundamento de una vida que no reniega de lo placentero y lo doloroso, de lo grande y lo pequeño, aparejados en la eternidad de lo que fue, pues solo mediante ese acto destructivo de los valores hasta ahora supremos puede llegarse al supremo querer que se erige en ley de sí mismo sin el lastre del resentimiento ni de la mala consciencia.

\section{Referencias}

Ávila Vásquez, M. (2015). De la metafísica de la música a la música en tiempos posmetafísicos o la música y el nihilismo. Cuestiones de filosofía, 1(17), pp. 15-37.

Cruz Vélez, D. (1985). Nihilismo e inmoralismo. R. Sierra Mejía (Ed.), La filosofía en Colombia (siglo XX) (pp. 101-124). Bogotá: Procultura.

Deleuze, G. (2002). Nietzsche y la filosofía. (Trad. C. Artal). Madrid: Editora Nacional.

Heidegger, M. (1995). La frase de Nietzsche «Dios ha muerto». Caminos del Bosque (Trad. H. Cortés y A. Leyte) (pp. 157-198). Madrid: Alianza.

Heidegger, M. (2013). Nietzsche. (Trad. J. L. Vermal). Barcelona: Ariel.

Nietzsche, F. (1972). La genealogía de la moral. Un escrito polémico. (Trad. A. Sánchez Pascual). Madrid: Alianza.

Nietzsche, F. (1973). Crepúsculo de los ídolos. (Trad. A. Sánchez Pascual). Madrid: Alianza.

Nietzsche, F. (1974). El Anticristo. (Trad. A. Sánchez Pascual). Madrid: Alianza.

Nietzsche, F. (1993). Así habló Zaratustra. (Trad. A. Sánchez Pascual). Barcelona: Altaya.

Nietzsche, F. (2002). La ciencia jovial (La gaya scienza) (Trad. J. Jara). Barcelona: Círculo de Lectores. 
Nietzsche, F. (2006). Fragmentos póstumos. Vol. IV (Trad. J. L. Vermal y J. Llinares). Madrid: Tecnos.

Nietzsche, F. (2011). El Nacimiento de la Tragedia (Trad. J. Llinares). Obras Completas Vol. I (pp. 329-438). Madrid: Tecnos.

Pérez Mantilla, R. (2000). El eterno retorno de lo mismo. Ideas y Valores, 49(114), pp. 3-19. 